\title{
Article
}

\section{Application of a Sediment Quality Index to the Masan Bay, Korea}

\author{
Won Joon Shim* and Sang Hee Hong \\ South Sea Research Institute, KORDI \\ Geoje 656-830, Korea
}

\begin{abstract}
A sediment quality index (SQI) and a mean sediment quality guideline quotient (M-SQGQ) were applied for the assessment of sediment quality in Masan Bay, Korea where metals and organic pollutants are of concern. The SQI was calculated by two functions, 'scope' (the number of variables that do not meet guideline objective) and 'amplitude' (the magnitude by which variables exceed guideline objective), with six different sediment quality guideline values from Canada, USA and Australia/New Zealand. Categorization of sediment quality was on the basis of SQI scores. The SQI values were compared with six guideline values applied as well as with the M-SQGQs. The SQI values were severely influenced by a few variables of high exceedance in the degree of non-compliance. The SQI values were very dependent on both the numbers and values of guideline variables used in index caluculation. Nevertheless, the SQI could provide integrated and simplified information from a large number of chemical data set. It is required to further evaluate protocols and guideline applied for deriving SQI and to compare it with field based sediment toxicity test and ecosystem integrity.
\end{abstract}

Key words : sediment quality index, sediment quality guideline, metals, organic pollutants

\section{Introduction}

Toxic contaminants introduced to estuarine and coastal environments are readily adsorbed to particulate matters and then settled down to sea bottom. This will elevate concentration levels of toxicants in marine sediment, which acts like a repository of toxic chemicals. Sedimentassociated contaminants such as heavy metals and organic toxicants cause adverse effects on benthic organisms, and can be relocated either by physical, chemical or biological means (Marvin et al. 2004). The contaminant relocation may also be expressed as bioaccumulation, when a contaminant moves from the sediment or sediment pore water into an organism, or as biomagnification, which results from a combination of bioaccumulation and trophic transfer. Sediment-associated contaminants are a major impediment to restoration and conservation of ecosystems in a heavily polluted embayment.

A large set of data are usually generated from environmental monitoring, which is difficult to analyze and

\footnotetext{
*Corresponding author. E-mail : wjshim@kordi.re.kr
}

interpret due to the complex inter-relationships between the measured values (Shin and Lam 2001). Such data are also often difficult to translate into simple terms so that an interested member of the policy makers and the public can understand the meaning of the monitoring results. To this end, the use of environmental indices can play an important role in the translation process of integrating complex technical data into understandable forms (Train 1972).

Many environmental indices derived from biological and (or) chemical data set have been developed and applied for water quality interpretation in the freshwater environment (Prati et al. 1971; Miller et al. 1986; Tyson and House 1988; Xu et al. 1999; Jarvie et al. 2002; Parr and Mason 2003; Jiang 2006) and in the saltwater environment (Read et al. 1982; Nocciolini et al. 2000; Hernandez-Romero et al. 2004; Xu et al. 2004). Some of these indices included physiochemical parameters in their formulations whereas other involved biological information only. However, there are only a few sediment quality indices published in the literature for classification of sediment conditions in freshwater (Garpentine et al. 2001; Marvin et al. 2004) and marine environments (Shin and 
Lam 2001).

Environmental monitoring of hazardous substances has been conducted in the coastal environment of Korea since 2000, which has generated several sets of data (MOMAF, 2002). However, there was no attempt to combine the chemical monitoring data to derive an integrated sediment quality index (SQI). Sediment quality index derived from toxicant levels in sediments requires not only numerical sediment quality guidelines, but also a protocol how to derive index from many guideline variables. Unfortunately, there is so far no numerical sediment quality guidelines and a protocol for deriving SQI in Korea. There is a growing concern in Korea for assisting environmental managers in priotizing pollution prevention, ranking environmentally degraded sites, determining temporal changes of environmental conditions, and communicating to public. In this context, we aim to apply SQI approach to Masan Bay, one of most polluted bays in Korea, where large and complex data set are produced through monitoring programs (KORDI 2007). For this purpose, sediment quality guidelines in Canada, USA and Australia/Newzealand were reviewed and compared. Deriving methodology of SQI in Canada (site specific SQI) and USA (hazard quotient approach) were compared and separately applied to Masan Bay. Based on the SQIs, sediment quality of Masan Bay was assessed and characterized, and SQI

Table 1. Sediment quality guidelines suggested by Canada, USA NOAA, and ANZECC and concentration range of contaminants in surface sediment from Masan ${ }^{a}$ Bay.

\begin{tabular}{|c|c|c|c|c|c|c|c|c|}
\hline \multirow{2}{*}{$\begin{array}{c}\text { Toxicant } \\
\text { (Unit) }\end{array}$} & & \multicolumn{2}{|c|}{ Canada } & \multicolumn{2}{|c|}{ US NOAA } & \multirow{2}{*}{\multicolumn{2}{|c|}{$\frac{\text { ANZECC }}{\text { ISQG-Low ISQG-High }}$}} & \multirow{2}{*}{ Masan } \\
\hline & & ISQG & PEL & ERL & ERM & & & \\
\hline Acenaphthene & $n g / g d w$ & 6.71 & 88.9 & 16 & 500 & 16 & 500 & $0.49-6.04$ \\
\hline Acenaphthylene & $n g / g d w$ & 5.87 & 128 & 44 & 640 & 44 & 640 & $0.44-1.70$ \\
\hline Anthracene & $n g / g d w$ & 46.9 & 245 & 85.3 & 1100 & 85 & 1100 & $0.86-5.88$ \\
\hline Benz[a]anthracene & $n g / g d w$ & 74.8 & 693 & 261 & 1600 & 261 & 1600 & $7.55-43.5$ \\
\hline $\begin{array}{l}\text { Benzo[a]pyrene }+ \\
\text { Benzo[b]fluoranthene }\end{array}$ & $n g / g ~ d w$ & 88.8 & 763 & 430 & 1600 & 430 & 1600 & $13.5-96.9$ \\
\hline Chrysene & $\mathrm{ng} / \mathrm{g} \mathrm{dw}$ & 108 & 846 & 384 & 2800 & 384 & 2800 & $10.0-50.3$ \\
\hline Dibenzo[a,h]anthracene & $n g / g d w$ & 6.22 & 135 & 63.4 & 260 & 63 & 260 & $0.27-6.52$ \\
\hline Fluoranthene & $n g / g d w$ & 113 & 1494 & 600 & 5100 & 600 & 5100 & $12.2-58.3$ \\
\hline Fluorene & $n g / g d w$ & 21.2 & 144 & 19 & 540 & 19 & 540 & $1.54-9.78$ \\
\hline 2-Methylnaphthalene & $n g / g d w$ & 20.2 & 201 & 70 & 670 & - & - & $4.58-41.1$ \\
\hline Naphthalene & $n g / g d w$ & 34.6 & 391 & 160 & 2100 & 160 & 2100 & $13.0-93.8$ \\
\hline Phenanthrene & $n g / g ~ d w$ & 86.7 & 544 & 240 & 1500 & 240 & 1500 & $5.50-29.8$ \\
\hline Pyrene & $n g / g d w$ & 153 & 398 & 665 & 2600 & 665 & 2600 & $11.8-78.7$ \\
\hline Lindane & $n g / g d w$ & 0.32 & 0.99 & - & - & 0.32 & 1 & n.d.-1.74 \\
\hline Chlordane & $n g / g d w$ & 2.26 & 4.79 & 0.5 & 6 & 0.5 & 6 & n.d.-1.01 \\
\hline p,p-DDD & $n g / g d w$ & 1.22 & 7.81 & 2 & 20 & 2 & 20 & $0.01-3.65$ \\
\hline $\mathrm{p}, \mathrm{p}-\mathrm{DDE}$ & $n g / g d w$ & 2.07 & 374 & 2.2 & 27 & 2.2 & 27 & $0.02-6.71$ \\
\hline $\mathrm{p}, \mathrm{p}-\mathrm{DDT}$ & $n g / g ~ d w$ & 1.19 & 4.77 & 1 & 7 & - & - & n.d.- 1.70 \\
\hline Dieldrin & $n g / g ~ d w$ & 0.71 & 4.3 & 0.02 & 8 & 0.02 & 8 & n.d.- -0.21 \\
\hline Endrin & $n g / g d w$ & 2.67 & 62.4 & - & - & 0.02 & 8 & n.d.-0.12 \\
\hline T-PCBs & $n g / g d w$ & 21.5 & 189 & 22.7 & 180 & 23 & - & $0.63-58.0$ \\
\hline Heptachlor epoxide & $n g / g d w$ & 0.6 & 2.74 & - & - & - & - & n.d.-0.06 \\
\hline PCDD/Fs & ngTEQ/g dw & 0.00085 & 0.0215 & - & - & - & - & n.d.-1.31 \\
\hline TBT & ng Sn/g dw & - & - & - & - & 5 & 70 & $6.00-165$ \\
\hline NPs & $\mathrm{ng} / \mathrm{g} \mathrm{dw}$ & 1 & - & - & - & - & - & $13.0-1930$ \\
\hline Zinc & $\mu \mathrm{g} / \mathrm{g} d w$ & 124 & 271 & 150 & 410 & 200 & 410 & $123-373$ \\
\hline Chromium & $\mu \mathrm{g} / \mathrm{g} \mathrm{dw}$ & 52.3 & 160 & 81 & 370 & 80 & 370 & $38.3-80.1$ \\
\hline Copper & $\mu \mathrm{g} / \mathrm{g} \mathrm{dw}$ & 18.7 & 108 & 34 & 270 & 65 & 270 & $20.5-78.0$ \\
\hline Arsenic & $\mu \mathrm{g} / \mathrm{g} \mathrm{dw}$ & 7.24 & 41.6 & 8.2 & 70 & 20 & 70 & $4.09-11.4$ \\
\hline Cadmium & $\mu \mathrm{g} / \mathrm{g} \mathrm{dw}$ & 0.7 & 4.2 & 1.2 & 9.6 & 1.5 & 10 & $0.10-2.35$ \\
\hline Lead & $\mu \mathrm{g} / \mathrm{g} \mathrm{dw}$ & 30.2 & 112 & 46.7 & 218 & 50 & 220 & $26.6-82.2$ \\
\hline
\end{tabular}

an.d.: not detected. 
application using foreign sediment quality guidelines and SQI protocols are also discussed.

\section{Materials and Methods}

\section{Sediment Quality Guidelines}

Many developed countries set up sediment quality guidelines to protect saltwater aquatic life from hazardous substances. Among them, Canadian Council of Ministers of the Environment (CCME), USA National Oceanic and Atmospheric Administration (NOAA) and Australian and New Zealand Environment and Conservation Council (ANZECC) establish numerical sediment quality guidelines which are derived from ecological risk assessment (CCME and ANZECC) or empirical field toxicity test along with chemical analysis (NOAA) (Table 1). European Union has Water Framework Directive (WFD) for strategic environmental management planning, which includes Environmental Quality Standards (EQS) of freshwater environment, and EQS for marine envrinment are under consideration. The sediment quality guidelines for marine environment from CCME, NOAA and ANZECC were compared and applied to derive SQI.

\section{Derivation of the Sediment Quality Index}

The derivation of site specific SQI followed the method proposed by Grapentine et al. (2002) which was modified from the Canadian Water Quality Index (CCME 2001).

$$
\begin{aligned}
& F_{1}=\left(\frac{\# \text { of failed variables }}{\text { total } \# \text { of variables }}\right) \times 100=\text { Scope } \\
& F_{3}=\left(\frac{m d n c}{(0.01 m d n c+0.01)}\right)=\text { Amplitude }
\end{aligned}
$$

Where

$$
\begin{gathered}
m d n c=\frac{\sum_{i=1}^{p} \text { non-compliance }_{i}}{\# \text { of tests }} \\
\text { non-compliance }_{i}=\left(\frac{\text { failed test value }_{i}}{\text { guideline }_{i}}\right)-1
\end{gathered}
$$

$m d n c$ : Mean degree of non-compliance;

$i \quad$ : Individual guideline;

$p \quad$ : Total number of guideline used.

$$
\mathrm{SQI}_{s}=100-\frac{\sqrt{F_{1}^{2}+F_{3}^{2}}}{\sqrt{2}}
$$

Grapentine et al. (2002) also proposed area average SQI with an additional function of $F_{2}$ (area frequency) as follows.

$$
\begin{aligned}
& F_{2}=\left(\frac{\# \text { of tests failed }}{\text { total } \# \text { of tests }}\right) \times 100=\text { Area frequency } \\
& \mathrm{SQI}_{a}=100-\frac{\sqrt{F_{1}^{2}+F_{2}^{2}+F_{3}^{2}}}{\sqrt{3}}
\end{aligned}
$$

To derive $F_{2}$ values for SQI, time series monitoring data at each site or regionally large number of data set to derive an average are required. Whereas, a total of 21 stations were surveyed in 2004 (KORDI 2007), which was not enough to calculate $F_{2}$ value. Thus, only site specific SQI can be applied in Masan Bay. To compare SQIs (hereafter SQI means site specific SQI) derived from different numerical sediment quality guideline values, the guidelines established by CCME, NOAA and ANZECC were used for calculating $F_{1}$ and $F_{3}$.

The SQI categories for classifying the index scores from 'poor' to 'excellent' suggested by Grapentine et al. (2002) and Marvin et al. (2004) were used. Sediments are classified according to the following: (1) excellent (SQI value of 95-100), (2) Good (SQI value of 80-94), (3) Fair (SQI value of 60-79), (4) Marginal (SQI value of 45-59), and Poor (SQI value of 0-44).

\section{Mean Sediment Quality Guideline Quotients}

Mean sediment quality guideline quotients (M-SQGQs) were defined as the ratio of the sediment contaminant concentration to the applicable guideline (Long and MacDonald 1998):

$$
\begin{aligned}
& \text { Mean SQGQ }=\frac{\sum_{i=1}^{n} \mathrm{SQG}_{i} \mathrm{Q}_{i}}{n} \\
& \text { SQG-Q }_{i}=\frac{\text { Concentration of Contaminant }}{\mathrm{SQG}_{i}}
\end{aligned}
$$

They were developed to represent the presence of chemical mixtures in sediments and are derived by normalizing a suite of chemicals to their respective numerical sediment quality guidelines. The M-SQGQ categories for classifying the quotient from 'non-toxic' to 'highly toxic' suggested by Long and MacDonald (1998) are used. Sediments are classified according to the following: (1) non-toxic (M-SQGQ value < 0.1), (2) marginally toxic $(0.1<$ M-SQGQ value < 1.0), (3) highly toxic (M-SQGQ value $>1.0$ ).

\section{Masan Bay Sediment Characterization}

Surveys of Masan Bay by Korea Ocean Research and 


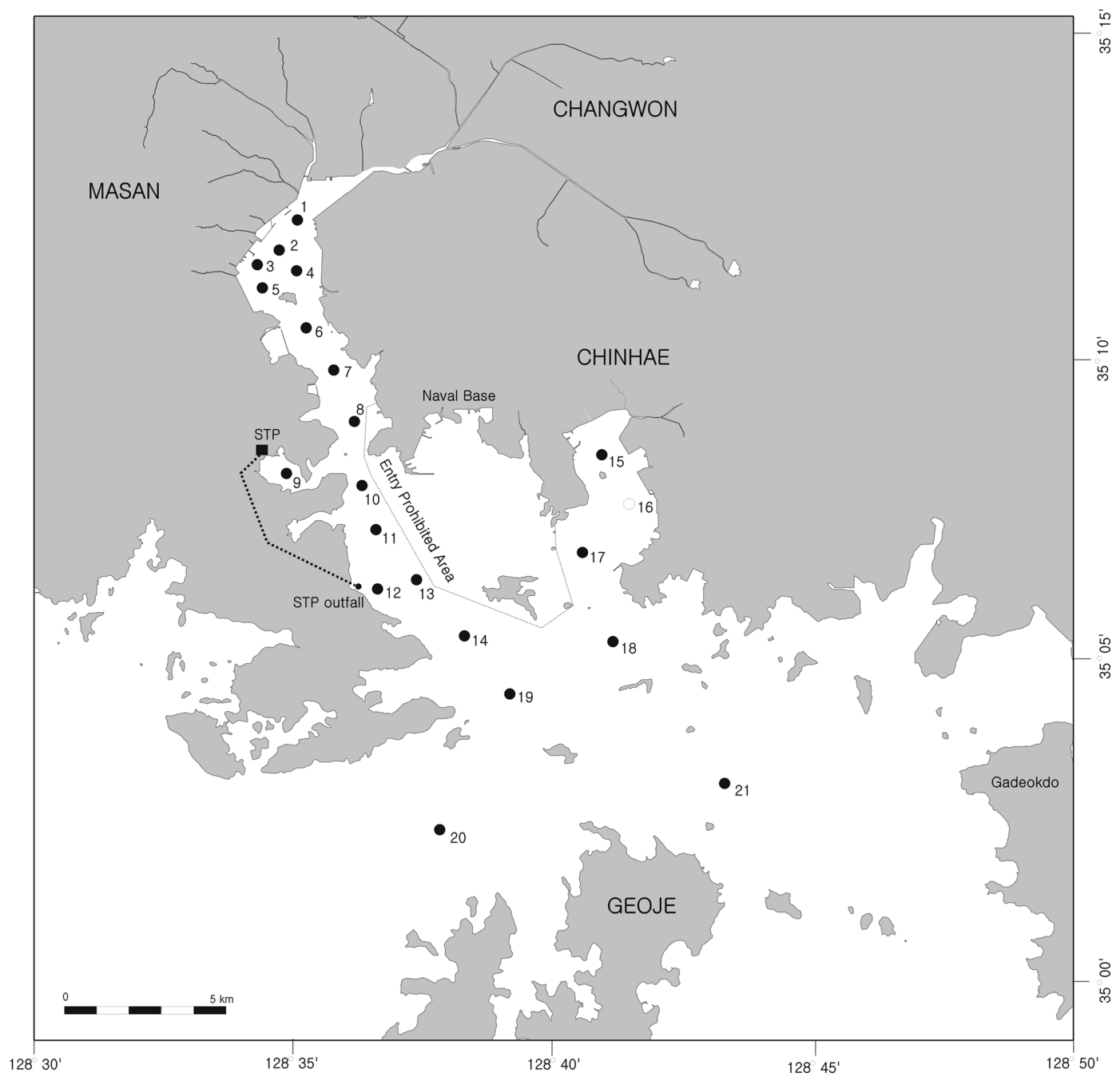

Fig. 1. Location map of surface sediment stations in Masan Bay.

Development Institute (KORDI) in 2004 produced the sediment contaminant data. Surficial sediment samples were collected using a Van veen Grab sampler from twenty-one stations in Masan Bay (Fig. 1). Sample sites ranged from the innermost part of the bay to the mouth of the bay. All samples collected from the surveys consisted of fine-grained sediments classified as clay and silt. The top $2 \mathrm{~cm}$ of sediment was sampled for analysis of persistent organic pollutants (POPs), metals, particle size characterization, and total organic carbon. The analytical methods for various toxicants such as organic pollutants (polychlorinated biphenyls, organochlorine pesticides, polychlorinated dibenzodioxins and dibenzofurans, polynuclear aromatic hydrocarbons, organotins, and nonylphenol) and heavy metals (zinc, chromium, copper, arsenic, cadmium and lead) are available elsewhere (KORDI 2007).
Masan Bay is a semi-enclosed embayment located in the southern part of Korea. This bay is surrounded by heavily populated cities and industrial complexes discharging significant amounts of contaminants into the bay. Discharges from municipal sewage treatment plant enter the bay through a underwater sewage diffuser nearby St. 12. The semi-enclosed nature of the bay leads to accumulation of pollutants in the bay.

\section{Results}

\section{Definition and Comparison of Sediment Quality Guidelines}

Sediment quality guidelines are not established yet in Korea. However, implementation of sediment quality guideline is under consideration in Korea, and it is expected that the guideline to protect aquatic life is going 
to be set in near future. In order to evaluate sediment quality in Masan Bay in this study, we consulted sediment quality guidelines from Canada, USA, and Australia/New Zealand. These guidelines were found to be good screening tools for assessing potential risks, and to assist in prioritizing sediment quality concerns. Thus we derived SQIs for Masan Bay from these guidelines as they are applicable to a broad suite of contaminants.

Canadian sediment quality guidelines were set to protect all forms of aquatic life and all aspect of their aquatic life cycles during an indefinite period of exposures to substances associated with bed sediment. CCME specified the guidelines as the "interim sediment quality guideline (ISQG)" and the "probable effect level (PEL)". Since the available substances being limited with information gaps, an ISQGs was suggested. Adverse biological effects are not expected when the measured concentrations of sediment associated chemicals are at or below the ISQG. The PEL represents the lower limit of the range of chemical concentrations that are usually or always associated with adverse biological effect. US NOAA sediment quality guidelines are set to evaluate and estimate the sediment contamination status. A vast amount of toxicological database and statistical approaches have been used to develop the 'effect' levels. NOAA specified the "effects range low" (ERL) and the "effects range median" (ERM) that is the determined values for each chemical as 10th and 50th percentile in a database of ascending concentrations associated with adverse biological effects, respectively. The ERL represents the chemical concentration below which an adverse effect would rarely be observed. The ERM represents the concentration above which adverse effect would frequently occur. ANZECC has derived the "ISQG-low" and the "ISQG-high" values, which correspond to the effects range-low and -median, respectively, used in NOAA. As the ANZECC guidelines were primarily based on the biological-effects database of North America, and the approach for establishment of the guidelines is similar to US NOAA with an additional application of ANZECC data, guideline values from ANZECC are much similar to those of US NOAA than that of Canada. However, the list of toxicants (2-Methylnaphthalene, lindane, p',p'-DDT, endrin, and tributyltin) are a little different between NOAA and ANZECC guidelines.

These guidelines include a variety of contaminant classes including heavy metals, organochlorine pesticides (OCPs), polychlorinated biphenyls (PCBs), polychlorinated dibenzo dioxins and dibenzofurans (PCDD/Fs), polynuclear aromatic hydrocarbons (PAHs), and so on. A list of contaminants used in the current study are shown in Table 1 , which includes thirty chemicals including heavy metals and organic contaminants. Among the three sediment quality guidelines, Canadian SQGs are relatively conservative because they were derived on the basis of the lowest effects concentration of contaminant. Canadian ISQG and PEL guidelines for PAHs are substantially lower than the US and ANZECC guidelines. However, for heavy metals and persistent organic contaminants such as PCBs and organochlorine pesticides, the three guidelines are relatively similar to each other and generally within a factor of two. The guideline value for heptachlor epoxide and PCDD/Fs are just developed by CCME. The value of $\mathrm{PCDD} / \mathrm{Fs}$ is much lower than other chemicals due to the highly toxic properties of PCDD/Fs. The guideline values for nonylphenols (NPs) and TBT are only suggested by Canada ISQG and ANZECC ISQGs, respectively.

\section{Spatial Distribution in Sediment Quality Index Values}

Heavy metals and organic toxicants listed in Table 1 were determined and used in calculation of individual SQIs values using the two-function equation that incorporated $F_{1}$ (scope) and $F_{3}$ (amplitude), the distribution of which is shown in Fig. 2. The SQI scores derived from different SQGs were in the range of 27-81 (CCME-ISQG), 53-100 (CCME-PEL), 65-100 (NOAA-ERL), and 53-97 (ANZECCISQG-low). All the SQI scores derived from NOAAERM and ANZECC-ISQG-high value were 100 and over 95 (classified as 'excellent') respectively (Fig. 2e and f), because none of variables targeted in Masan Bay exceeded NOAA-ERM values and only tributyltin (TBT) concentrations were slightly over ANZECC-ISQG-high value at five stations in Masan Bay. Even though each SQG have different set of chemicals and numerical values, the SQI scores showed an increasing trend from the inner to the outer Masan Bay except for NOAA-ERM based SQI. At stations near the input sources such as the inner Masan Bay (Sts. 3 and 5), the inner Haengam Bay (Sts. 15 and 16) and sewage ocean outfall (Sts. 11 and 12), SQI scores were relatively low compared to the other stations surveyed (Fig. 2b, c, and e). Spatial trends in sediment quality in Masan Bay reflected overall the distribution pattern of individual contaminant classes such as PCBs, PAHs, TBT, DDTs and zinc.

\section{Factors Affecting Sediment Quality Index Values}

Concentrations of PCDD/Fs in Masan Bay were several orders magnitude higher than the CCME-ISQG value at all 
(a)

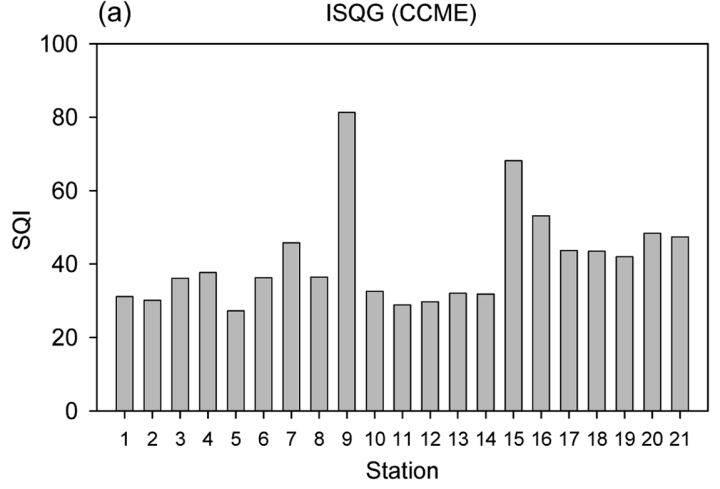

(c)

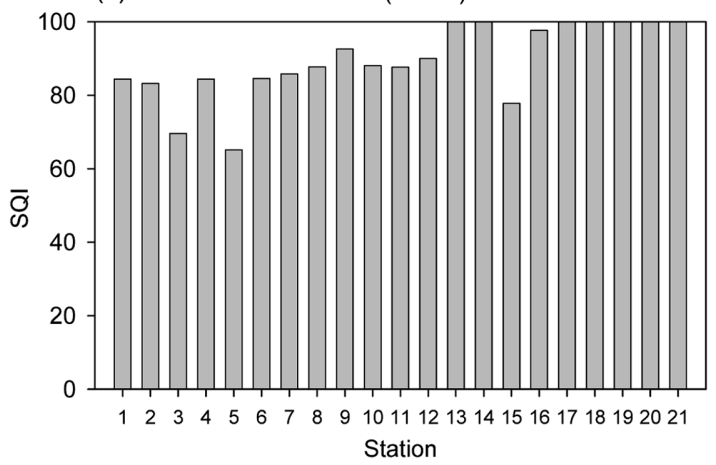

(e) ISQG low (ANZECC)

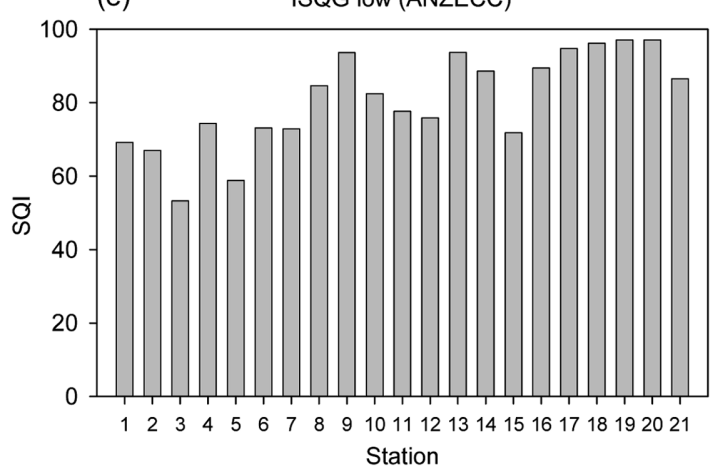

(b)

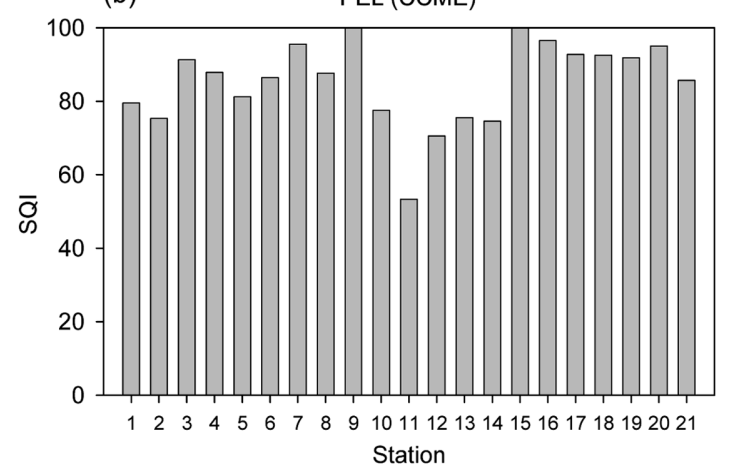

(d)

ERM (NOAA)
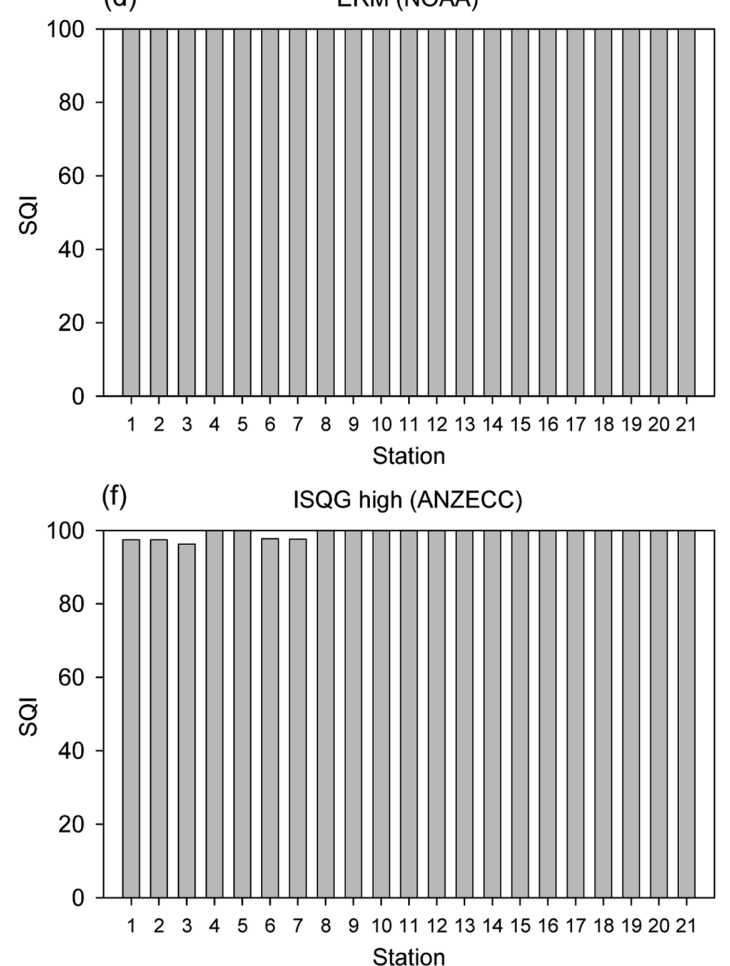

Fig. 2. Sediment quality index (SQI) of Masan Bay derived from (a) CCME interim sediment quality guideline (ISQG), (b) CCME probable effect level (PEL), (c) NOAA effect range low (ERL), (d) NOAA effect range median (ERM), (e) ANZECC interim sediment quality guideline low (ISGQ-low), and (f) ANZECC interim sediment quality guideline high (ISGQ-high).

the stations surveyed (Tables 1 and 2). Thus, PCDD/Fs heavily influenced both the $F_{1}$ and $F_{3}$ values especially with the degree of non-compliance ([failed test value $\mathrm{i}_{\mathrm{i}} /$ guideline $\mathrm{i}_{\mathrm{i}}$-1) up to 1536 , when the CCME-ISQG values was applied for deriving the SQI. Six heavy metals, PAHs, PCBs, and OCPs (e.g. DDTs) were variable that frequently exceeded the CCME-ISQG values (Table 2). Total 15, 13, and 11 variables were over the CCME-ISQG values at Sts. 5, 3 and 15 respectively, which was $37-50 \%$ of exceedance in the $F_{1}$ function. The concentrations of $\mathrm{PCDD} / \mathrm{Fs}$ in Masan Bay sediment were over the CCME-
PEL values at 19 out of 21 stations surveyed, and zinc were over the value at four stations. Exceedance of PCDD/Fs were more than an order of magnitude higher than the CCME-PEL values, which mainly affected the $F_{3}$ values. Although only two variables (PCDD/Fs and zinc) were taken into account for the $F_{1}$ values in SQI from CCMEPEL, high $F_{3}$ values influenced by PCDD/Fs resulted in SQI classified as 'marginal' at one station and 'fair' at six stations (Table 3).

Five heavy metals other than chromium, PCBs and OCPs frequently exceeded the NOAA-ERL values (Table 
Table 2. Percentage of stations exceeding (\%) sediment quality guideline value.

\begin{tabular}{|c|c|c|c|c|c|c|}
\hline \multirow{2}{*}{ Variables } & \multicolumn{2}{|c|}{ Canada } & \multicolumn{2}{|c|}{ US EPA/NOAA } & \multicolumn{2}{|c|}{ ANZECC } \\
\hline & ISQG & PEL & ERL & ERM & ISQG-Low & ISQG-High \\
\hline Acenaphthene & 0 & 0 & 0 & 0 & 0 & 0 \\
\hline Acenaphthylene & 0 & 0 & 0 & 0 & 0 & 0 \\
\hline Anthracene & 0 & 0 & 0 & 0 & 0 & 0 \\
\hline Benz[a]anthracene & 0 & 0 & 0 & 0 & 0 & 0 \\
\hline $\begin{array}{l}\text { Benzo[a]pyrene }+ \\
\text { Benzo[b]fluoranthene }\end{array}$ & 5 & 0 & 0 & 0 & 0 & 0 \\
\hline Chrysene & 0 & 0 & 0 & 0 & 0 & 0 \\
\hline Dibenzo[a,h]anthracene & 5 & 0 & 0 & 0 & 0 & 0 \\
\hline Fluoranthene & 0 & 0 & 0 & 0 & 0 & 0 \\
\hline Fluorene & 0 & 0 & 0 & 0 & 0 & 0 \\
\hline 2-Methylnaphthalene & 33 & 0 & 0 & 0 & - & - \\
\hline Naphthalene & 43 & 0 & 0 & 0 & 0 & 0 \\
\hline Phenanthrene & 0 & 0 & 0 & 0 & 0 & 0 \\
\hline Pyrene & 0 & 0 & 0 & 0 & 0 & 0 \\
\hline Lindane & 19 & 0 & - & - & 19 & 5 \\
\hline Chlordane & 0 & 0 & 5 & 0 & 5 & 0 \\
\hline p,p-DDD & 19 & 0 & 14 & 0 & 14 & 0 \\
\hline $\mathrm{p}, \mathrm{p}-\mathrm{DDE}$ & 14 & 0 & 14 & 0 & 14 & 0 \\
\hline $\mathrm{p}, \mathrm{p}-\mathrm{DDT}$ & 10 & 0 & 10 & 0 & - & - \\
\hline Dieldrin & 0 & 0 & 57 & 0 & 57 & 0 \\
\hline Endrin & 0 & 0 & - & - & 19 & 0 \\
\hline T-PCBs & 24 & 0 & 24 & 0 & 24 & - \\
\hline Heptachlor epoxide & 0 & 0 & - & - & - & - \\
\hline $\mathrm{PCDD} / \mathrm{Fs}$ & 100 & 90 & - & - & - & - \\
\hline TBT & - & - & - & - & 100 & 24 \\
\hline NPs & 5 & - & - & - & - & - \\
\hline Zinc & 95 & 19 & 67 & 0 & 52 & 0 \\
\hline Chromium & 95 & 0 & 0 & 0 & 5 & 0 \\
\hline Copper & 100 & 0 & 62 & 0 & 19 & 0 \\
\hline Arsenic & 57 & 0 & 38 & 0 & 0 & 0 \\
\hline Cadmium & 57 & 0 & 43 & 0 & 24 & 0 \\
\hline Lead & 90 & 0 & 43 & 0 & 33 & 0 \\
\hline
\end{tabular}

2). More than 8 variables ( $>38 \%$ exceedance) were the ERL values at Sts. 3, 5 and 15 in which SQI scores were relatively low (Fig. 2c). Zinc, copper, PCBs and Dieldrin were major variables influencing the degree of noncompliance. All the heavy metals and toxic compound levels in Masan Bay sediment were well below the NOAA-ERM values (Table 2), and then all the SQI scores at twenty one stations derived from NOAA-ERM were classified as 'excellent' (Fig. 2d, Table 3).

Total 13 out of 26 ANZECC-ISQG-low variables taken into calculation of SQI did not comply the set values in Masan Bay sediments (Table 2). Tributyltin, one of organometallics, was a major variable in both the $F_{1}$ (100\% exceedance) and $F_{3}$ (up to 32 in the degree of noncompliance). Because the SQGs of CCME and NOAA do not include TBT, it can not be taken into account for SQI derivation from CCME-ISQG, CCME-PEL, NOAA-ERL and NOAA-ERM. Dieldrin was the second influencing variable in SQI derived from ANZECC-ISQG-low, which was followed by four heavy metals (zinc, copper, cadmium and lead) and PCBs. The numerical values of ANZECCISQG-low for PAHs, p,p-DDD, and PCBs, are identical to the NOAA-ERL values and the other variables are within a similar concentration range (Table 1), because they were directly adopted or slightly modified from the NOAAERL values. Therefore, even if number and item of variables such as TBT in NOAA-ERL and ANZECC-ISQG-low are different, the final SQI scores derived from both the NOAA-ERL and ANZECC-ISQG-low values are positively correlated ( $r=0.97 ; p<0.001)$ (Fig. $2 \mathrm{c}$ and 2e). Because 
Table 3. Comparison of sediment quality rankings for each evaluation method for Masan Bay including sediment quality index (SQI) and mean sediment quality guideline quotient (SQGQ). Sediments are ranked in the order of decreasing sediment quality.

\begin{tabular}{|c|c|c|c|c|c|c|c|c|c|}
\hline \multirow{3}{*}{$\begin{array}{c}\begin{array}{c}\text { Deriving } \\
\text { method }\end{array} \\
\text { Station }\end{array}$} & \multicolumn{6}{|c|}{$\begin{array}{l}\text { Sediment Quality Index }{ }^{\mathrm{a}} \\
\text { (Canada CCME) }\end{array}$} & \multicolumn{3}{|c|}{$\begin{array}{l}\text { Mean ERM-Quotient }^{\mathrm{b}} \\
\text { (US NOAA) }\end{array}$} \\
\hline & \multicolumn{2}{|c|}{ CCME } & \multicolumn{2}{|c|}{ NOAA } & \multicolumn{2}{|c|}{ ANZECC } & \multirow{2}{*}{$\frac{\text { NOAA }}{\text { ERM-Q }}$} & \multirow{2}{*}{$\begin{array}{l}\text { CCME } \\
\text { PEL-Q }\end{array}$} & \multirow{2}{*}{$\begin{array}{c}\text { ANZECC } \\
\text { ISQG High-Q }\end{array}$} \\
\hline & ISQG & PEL & ERL & ERM & ISQG low & ISQG high & & & \\
\hline 1 & 5 & 3 & 2 & 1 & 3 & 1 & 1 & 2 & 2 \\
\hline 2 & 5 & 3 & 2 & 1 & 3 & 1 & 1 & 2 & 2 \\
\hline 3 & 5 & 2 & 3 & 1 & 4 & 1 & 2 & 2 & 2 \\
\hline 4 & 5 & 2 & 2 & 1 & 3 & 1 & 1 & 2 & 2 \\
\hline 5 & 5 & 2 & 3 & 1 & 4 & 1 & 2 & 2 & 2 \\
\hline 6 & 5 & 2 & 2 & 1 & 3 & 1 & 1 & 2 & 2 \\
\hline 7 & 4 & 1 & 2 & 1 & 3 & 1 & 1 & 2 & 2 \\
\hline 8 & 5 & 2 & 2 & 1 & 2 & 1 & 1 & 2 & 1 \\
\hline 9 & 2 & 1 & 2 & 1 & 2 & 1 & 1 & 1 & 1 \\
\hline 10 & 5 & 3 & 2 & 1 & 2 & 1 & 1 & 2 & 1 \\
\hline 11 & 5 & 4 & 2 & 1 & 3 & 1 & 1 & 3 & 1 \\
\hline 12 & 5 & 3 & 2 & 1 & 3 & 1 & 1 & 2 & 2 \\
\hline 13 & 5 & 3 & 1 & 1 & 2 & 1 & 1 & 2 & 1 \\
\hline 14 & 5 & 3 & 1 & 1 & 2 & 1 & 1 & 2 & 1 \\
\hline 15 & 3 & 1 & 3 & 1 & 3 & 1 & 1 & 2 & 2 \\
\hline 16 & 4 & 1 & 1 & 1 & 2 & 1 & 1 & 2 & 1 \\
\hline 17 & 5 & 2 & 1 & 1 & 1 & 1 & 1 & 2 & 1 \\
\hline 18 & 5 & 2 & 1 & 1 & 1 & 1 & 1 & 2 & 1 \\
\hline 19 & 5 & 2 & 1 & 1 & 1 & 1 & 1 & 2 & 1 \\
\hline 20 & 4 & 1 & 1 & 1 & 1 & 1 & 1 & 2 & 1 \\
\hline 21 & 4 & 1 & 1 & 1 & 2 & 1 & 1 & 2 & 2 \\
\hline
\end{tabular}

${ }^{\mathrm{a}} 1$ (Excellent, SQI 95-100); 2 (Good, SQI 80-94); 3 (Fair, SQI 60-79); 4 (Marginal, SQI 45-59); 5 (Poor, SQI 0-44).

${ }^{\mathrm{b}} 1$ (Nontoxic, mean SQGQ $<0.1$ ); 2 (Marginally toxic, $0.1<$ mean SQGQ $<1$ ); 3 (Highly toxic, mean SQGQ $>1$ ).

the ANZECC-ISQG-high values are directly adopted from the NOAA-ERM values, those two SQGs are almost identical with a slight difference of cadmium and lead. However, contaminants listed in both the SQGs are slightly different: 2-methylnaphthalene, p,p-DDT, and PCBs (NOAAERM only); lindane, endrin, and TBT (ANZECC-ISQGhigh only). When the ANZECC-ISQG-high values were applied to calculate SQI in Masan Bay sediment, TBT was a variable exceeding the guideline value $(24 \%$ of stations) at five stations from the inner Masan Bay (Sts. 13, 6-7) (Table 2). Lindane concentration at St. 21 was over ANZECC-ISQG-high. The SQI from ANZECC-ISQGhigh at twenty one stations surveyed, however, fell in the classification of 'excellent' (Fig. 2f).

The relationship of two functions $\left(F_{1}\right.$ and $\left.F_{3}\right)$ in CCME SQI equations are compared among the four different trials for the SQI derivation using the CCME-ISQG, -PEL, NOAA-ERL and ANZECC-ISQG-low values (Fig. 3). The mean degree of compliance as amplitude in $F_{3}$ influenced much more than $F_{1}$ in the SQI from CCMEISQG and -PEL, because of PCDD/Fs. On the other hand, both $F_{1}$ and $F_{3}$ contribute more evenly to derive the SQI values from the NOAA-ERL and ANZECC-ISQG-low.

\section{Comparison of SQI and Mean SQGQs}

Mean sediment quality guideline quotients (M-SQGQs) are developed to represent the presence of chemical mixtures in sediments (Long and MacDonald 1998) and they were calculated in Masan Bay sediment from chemical concentrations and their SQG values of CCME-PEL, NOAA-ERM and ANZECC-ISQG-high. The M-SQGQs incorporate the number of SQGs exceeded and the degree to which they exceed and are used for comparison with observed biological effects in the laboratory or field (Fairey et al. 2001). The M-SQGQ was firstly developed with NOAA-ERM values which were empirically derived SQGs with field based toxicity test and chemical analysis (Long and MacDonald 1998). In this study, the SQG 
(a)

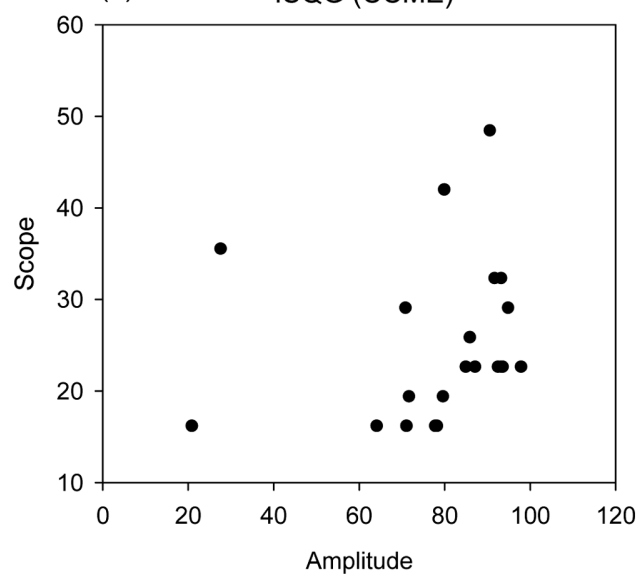

(c)

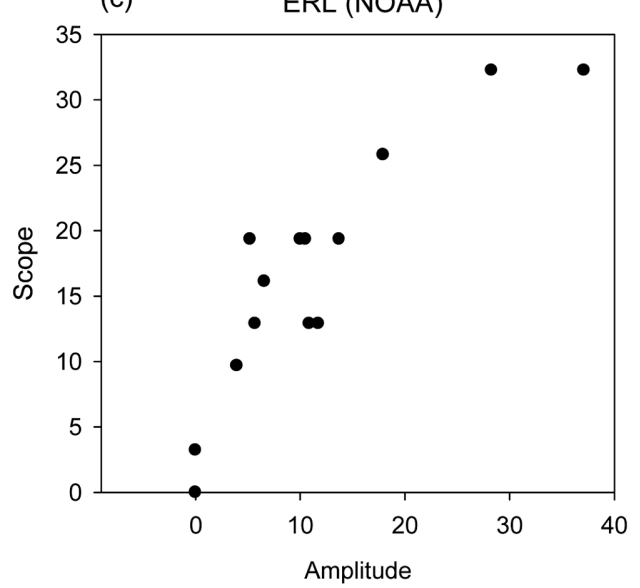

(b)

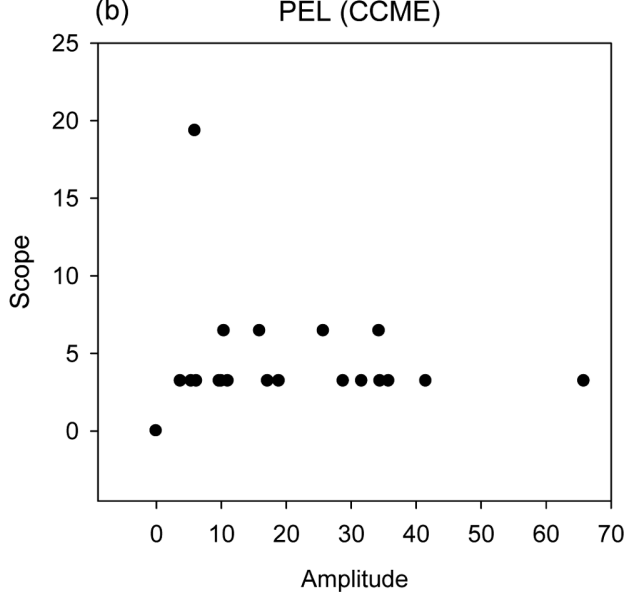

(d)

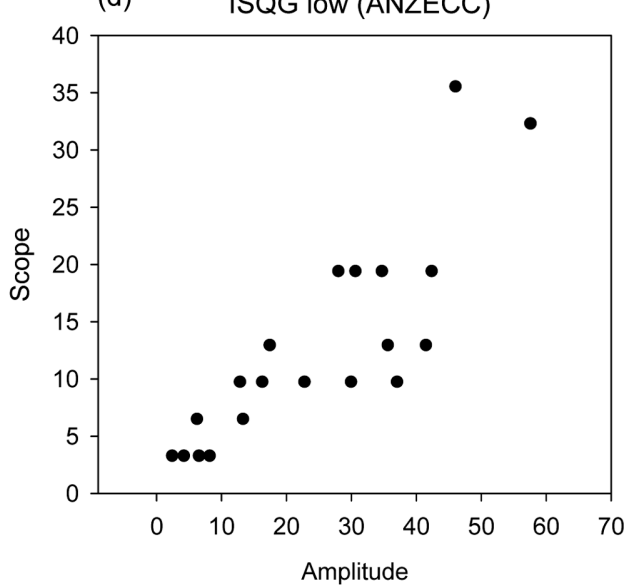

Fig. 3. Relationship between F1 (scope) and F3 (amplitude) values of sediment quality index (SQI) derived from (a) CCME interim sediment quality guideline (ISQG), (b) CCME probable effect level, (c) NOAA effect range low, and (d) ANZECC interim sediment quality guideline low (ISQG-low).

values (CCME-PEL, NOAA-ERM, and ANZECC-ISQGhigh), an indicator of probable adverse biological effects, are used to indirectly infer the probable toxic impact in the study area. All the M-SQGQs from the CCME-PEL ranged 0.1-2.2, and these relatively high values were mostly come from high exceedance of PCDD/Fs concentrations in Masan Bay over the CCME-PEL values (Fig. 4). The M-SQGQs from the NOAA-ERM and ANZECCISQG-high values were in the range of 0.04-0.13 and 0.04-0.20, respectively.

The spatial distribution of the M-SQGQs from the CCME-PEL showed that the highest quotient peak at stations near the sewage outfall and relatively high quotient values in the inner bay than the outer bay. The M-SQGQs from the NOAA-ERM and the ANZECC-ISGQ-high were slightly different in their values, but their spatial distribution patterns are very similar. It demonstrated that apparent decreasing trend of quotient values from the inner to the outer bay with additional hot spots at St. 12 (sewage ocean outfall), St. 15 (Haengam Bay), and St. 21. The exceptionally high quotient at St. 21 resulted from relatively high concentration of lindane.

Sediment quality rankings for each evaluation method for Masan Bay including SQI and M-SQGQs are presented in Table 3. Because of high exceedance of PCDD/Fs in CCME-ISQG derived SQI, 15 out of 21 stations in Masan Bay were classified as poor condition. The other stations were in marginal to fair condition except for St. 9 which was in good category. All the stations were excellent with the SQI values from the NOAA-ERM and ANZECCISQG-high. The SQI derived from the CCME-PEL, NOAAERL and ANZECC-ISQG-low can differentiate sediment quality in Masan Bay from marginal (or fair) to excellent condition. The sediment quality ranking by the SQI from the NOAA-ERL and the ANZECC-ISQG-low match well with the M-SQGQ from the NOAA-ERM at Sts. 3 and 5 

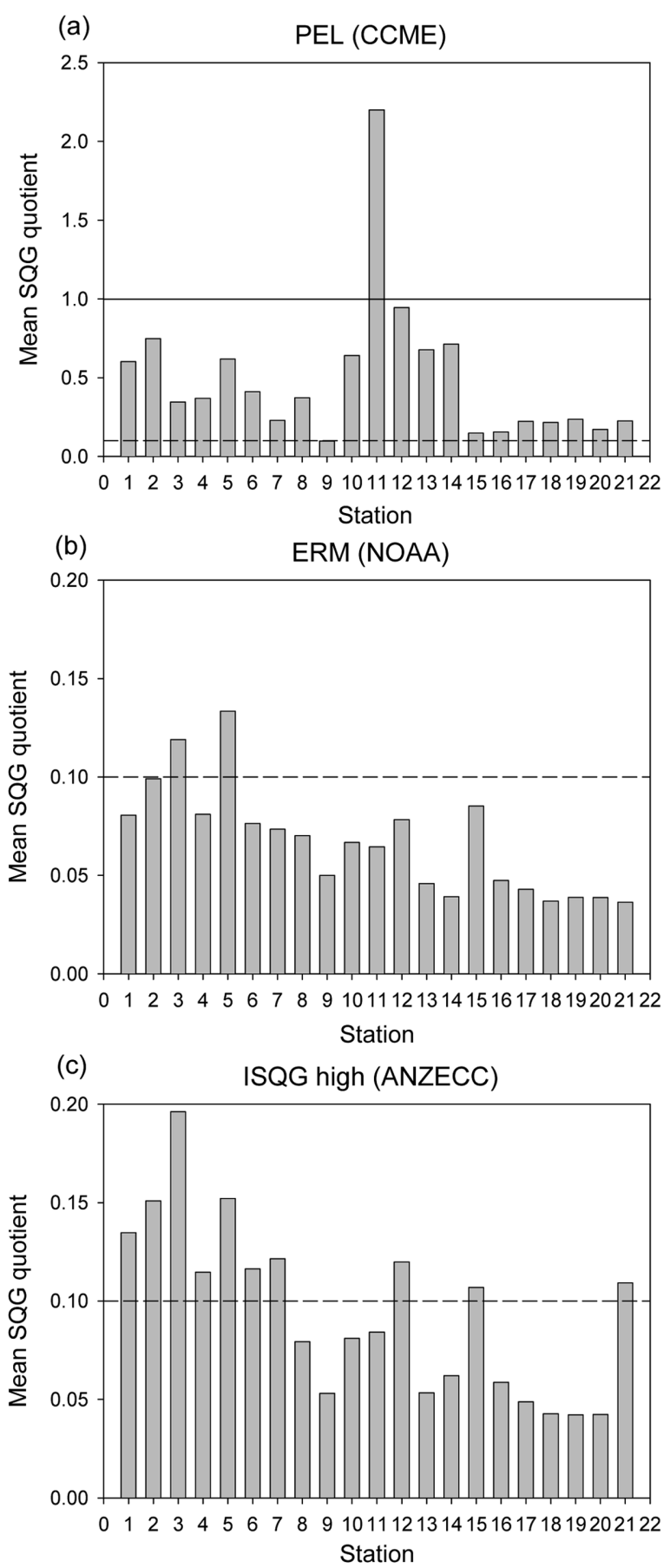

Fig. 4. Mean sediment quality guideline quotients (SQGQs) of Masan Bay derived from (a) CCME probable effect level (PEL), (b) NOAA effect range median (ERM), and (c) ANZECC interim sediment quality guideline high (ISQG-high). Dotted line indicates mean SQGQ of 0.1 and solid line indicates mean SQGQ of 1.

in which the SQGQ were classified as marginal toxic condition. In addition, spatial distribution pattern of the sediment quality ranking from the SQI of the NOAA-
ERL and ANZECC-ISQG-low were more or less similar with that of the mean SQGQ from the ANZECC-ISQGhigh.

\section{Discussion}

Sediment quality index was applied for the first time to Korean coastal environment to evaluate and to assess the quality of the sediment in an integrated way. Total 31 contaminants at 21 stations in Masan Bay (total 651 matrix) were interpreted case by case at each stations. Several multivariate statistical analysis such as principal component analysis can also be applied complementarily to explain the large data set. However, those scientific interpretation produce results that are still complicated to decision makers, local authorities, end users and general public. Indexing a large data set in a classified ranking is easy to follow and to get an overview on the status of contamination in the study area. However, the procedure of deriving SQI value requires steps of simplification of complex inter-relations in the data, which invariably mislead and (or) dilute the meaning of the data, at least some times.

The application of CCME-ISQG and -PEL values for deriving SQI in Masan Bay demonstrates a deviant result which comes from very low SQG score for PCDD/Fs. The range of the SQI from CCME-ISQG increased from 27-81 to 56-90 with removal of $\mathrm{PCDD} / \mathrm{Fs}$ variable. In addition, spatial distribution pattern of the SQI derived from CCME-ISQG without PCDD/Fs is changed to the pattern from that of NOAA-ERL and the ANZECCISGQ-low. Garpentine et al. (2002) have pointed that the squared nature of the mathematical functions used to generate the CCME SQI can result in dramatic decreases in the SQI values as the mean degree of non-compliance $\left(F_{3}\right)$ with the guideline increases. This effect is particularly severe when a relatively small number of variables exceed the guidelines. PCDD/Fs in the SQI from the CCMEISQG and -PEL or TBT in the SQI from the ANZECCISQG-low and -high are such variables influencing the SQI values. However, the nature of the CCME SQI can also result in categorization of sediment quality as poor when small guideline exceedances are frequent $\left(F_{1}\right)$. This is in the case of St. 5 in Masan Bay where maximum number of exceedance are recorded in the SQIs from CCME-ISQG, -PEL, NOAA-ERL, and ANZECC-ISGQlow. The SQI values are relatively low at St. 5 with different guideline values. Therefore, it is crucial that the parameter set and guideline values selected are relevant to 
Masan Bay in which the index is applied. The indexing methodology could be complemented by cursory statistical evaluations of the individual variables, and a comparison of SQI values calculated for appropriate reference sites.

The SQI is developed to summarize a large number of contaminant monitoring data set, which would be compared to other sediment toxicity and benthic community data. Even if SQGs that are incorporated in SQI caluculation are derived from ecological risk assessment and (or) field based toxicity test and chemical analysis, it is not sure that they exactly reflect sediment conditions and bioavailibilty of toxicants in the study area by area. The simplified SQIs may mislead to evaluate sediment quality in the study area. Therefore, interpretation of SQIs are often accompanying with field toxicity and benthic community data. Sediment toxicity test such as sea urchin fertilization with pore water and yeast estrogenicity with organic solvent extracts and diversity of benthic macrofauna (KORDI 2007) demonstrated positive relationships with the concentrations of toxic contaminants at stations near input sources such as the inner Masan Bay, Haengam Bay and sewage ocean outfall in the study area. Further evaluation is required to compare the SQI values derived from contaminant concentrations with field based sediment toxicity test and benthic ecosystem integrity.

The applicability of some guidelines may be called into question, particularly when a supplementary method such as principal component analysis does not indicate significant differences between test sites and reference site. Very area-specific background concentrations of copper affected the CCME SQI values in the Great Lakes (Marvin et al. 2004). In this study, even if exceedance of heavy metal concentrations over the CCME-ISQG, NOAAERL, and ANZECC-ISGQ-low were predominant in Masan Bay, background levels of metals in the bay were not taken into account. It is required to establish a site-specific background concentration of metals in the coastal environment of Korea and a number of contaminant concentration data set in reference sites for further comparison.

It was revealed that a few key variable severely influenced the final SQI values according to which SQG was applied in the SQI deriviation. In case of Korea, SQGs are not established yet, and SQG deriving methodology and procedure are not set up, either. Selection of SQGs is more critical than selection of a protocol for SQI calculation. Therefore, it is urgently required to set directly applicable Korean SQGs, which is derived from both toxicity data including at least several endemic speicies of Korea and monitoring data of toxic chemicals including at least toxicants exceeding the SQG values of foreign countries. Futhermore, it needs to be validated in Korea coastal environment.

\section{Acknowledgement}

This work was supported by grants-in-aid from Korea Ocean Research and Development Institute (Project No. PE971-04). Authors thank Dr. Narayanan Kannan and two anonymous reviewers for their valuable comments.

\section{References}

CCME. 2001. Canadian Water Quality Guidelines for the Protection of Aquatic Life: Canadian Water Quality Index 1.0, Technical Report. In: Canadian Environmental Quality Guidelines, 1999. Canadian Council of Ministers of the Environment, Winnipeg, Manitoba, Canada.

Fairey, R., E.R. Long, C.A. Roberts, B.S. Anderson, B.M. Phillips, J.W. Hunt, H.R. Puckett, and C.J. Wilson. 2001. An evolution of methods for calculating mean sediment quality guideline quotients as indicators of contamination and acute toxicity to amphipods by chemical mixtures. Environ. Toxicol. Chem., 20, 2276-2286.

Garpentine, L., C. Marvin, and S. Painter. 2002. Initial development and evaluation of a sediment quality index for the Great Lakes region. Hum. Ecol. Risk Assess., 8, 1549-1567.

Hernández-Romero, A.H., C. Tovilla-Hernández, E.A. Malo, and R. Bello-Mendoza. 2004. Water quality and presence of pesticides in a tropical coastal wetland in southern Mexico. Mar. Pollut. Bull., 48, 1130-1141.

Jarvie, H.P., E. Lycett, C. Neal, and A. Love. 2002. Patterns in nutrient concentrations and biological quality indices across the upper Thames river basin, UK. Sci. Total Environ., 282/283, 263-294.

Jiang, J.-G. 2006. Development of a new biotic index to assess freshwater pollution. Environ. Pollut., 139, 306317.

Korea Ocean Research and Development Institute. 2007. Marine environmental risk assessment of special management area: Masan Bay case study. Technical Report. KORDI, Ansan, Korea. (In Korean)

Long, E.R. and D.D. MacDonald. 1998. Recommended uses of empirically derived, sediment quality guidelines for marine and estuarine ecosystems. Hum. Ecol. Risk Assess., 4, 1019-1039.

Marvin, C., L. Grapentine, and S. Painter. 2004. Application of a sediment quality index to the lower Laurentian Great Lakes. Environ. Monit. Assess., 91, 1-16.

Miller, W.W., H.M. Joung, C.N. Mahannah, and J.R. Garrett. 1986. Identification of water quality differences in Nevada through index application. J. Environ. Quality, $15,265-271$. 
Ministry of Maritime Affairs and Fisheries. 2002. Nationwide monitoring study on POPs pollution in the Koran coastal environment. BSPM 125-00-1442-4. Technical Report. MOMAF, Seoul, Korea. (In Korean)

Nicciolini, S., L. Spadafina, M.R. Vacri, and E. Bacci. 2000. A simple bacterial index for relative water quality: Preliminary application in the Orbetello lagoon (Tuscany, Italy). Chemosphere, 41, 1065-1069.

Parr, L.B. and C.F. Mason. 2003. Long-term trends in water quality and their impact on macroinvertebrate assemblages in eutrophic lowland rivers. Wat. Res., 37, 29692979.

Prati, L., R. Pavanello, and F. Pesarin. 1971. Assessment of surface water quality by a single index of pollution. Wat. Res., 5, 741-751.

Read, P.A., K.J. Anderson, J.E. Matthews, P.G. Watson, M.C. Halliday, and G.M. Shields. 1982. Water quality in the firth of forth. Mar. Pollut. Bull., 13, 421-425.
Shin, P.K.S. and W.K.C. Lam. 2001. Development of a marine sediment pollution index. Environ. Pollut., 113, 281-291.

Train, R.E. 1972. The quest for environmental indices. Science, 178, 121.

Tyson, J.M. and M.A. House. 1988. The application of a water quality index to river management. Wat. Sci. Technol., 21, 1149-1159.

Xu, F.L., S.E. Jørgensen, and S. Tao. 1999. Ecological indicators for assessing ecosystem health. Ecol. Model., 116, 77-106.

Xu, F.L., K.C. Lam, Z.Y. Zhao, W. Zhan, Y.D. Chen, and S. Tao. 2004. Marine coastal ecosystem health assessment: A case study of the Tolo Harbour, Hong Kong, China. Ecol. Model., 355-370. 